\title{
Isolation and Characterization of Methanocorpusculum labreanum sp. nov. from the LaBrea Tar Pits
}

\author{
YIZHANG ZHAO,${ }^{1}+$ DAVID R. BOONE,$^{2 *}$ ROBERT A. MAH, ${ }^{1}$ JANE E. BOONE, ${ }^{1}$ AND LUYING XUN ${ }^{1}$ \\ Division of Environmental and Occupational Health Sciences, School of Public Health, University of California at Los \\ Angeles, Los Angeles, California 90024, ${ }^{1}$ and Environmental Science and Engineering, Oregon Graduate Center,
} Beaverton, Oregon $97006-1999^{2}$

\begin{abstract}
A new species of coccoid methanogen was isolated from the surface sediments of Tar Pit Lake at the LaBrea Tar Pits in Los Angeles, Calif. Surface colonies of strain $Z^{T}\left(=O G C 1^{T}\right)(T=$ type strain) were tan, circular, clear, and convex with entire edges. The cells were irregular, nonmotile, and coccoid (diameter, 0.4 to $2.0 \mu \mathrm{m}$ ) and grew by producing methane from $\mathrm{H}_{2}-\mathrm{CO}_{2}$ or formate but not from methanol, methylamines, or acetate. They exhibited a negative Gram reaction, had protein cell walls, and were susceptible to lysis by sodium dodecyl sulfate. They grew over a narrow pH range (pH 6.5 to 7.5 ), with fastest growth near pH 7 , and they were mesophilic (growth was most rapid at $37^{\circ} \mathrm{C}$ ). Cells grew fastest with $15 \mathrm{~g}$ or less of NaCl per liter of medium. We propose that this isolate be named as a new species of methanogen, Methanocorpusculum labreanum, with strain Z (= Oregon Graduate Center Collection strain OGC $1=$ DSM 4855) as the type strain.
\end{abstract}

Until recently, new species of coccoid $\mathrm{H}_{2}$-utilizing methanogenic bacteria were assigned to one of two genera, Methanococcus or Methanogenium, based mainly on their guanine-plus-cytosine $(\mathrm{G}+\mathrm{C})$ contents $(2,9,13,15,16)$. Recently, Methanocorpusculum parvum was described as a new genus and species; this coccoid organism might have been placed in the genus Methanogenium except that $16 \mathrm{~S}$ ribosomal ribonucleic acid cataloging data indicated that it was significantly different from Methanogenium cariaci, the type species of that genus (18). Deoxyribonucleic acid (DNA)-DNA hybridization studies (L. Xun, D. R. Boone, and R. A. Mah, submitted for publication) showed great diversity among the species of Methanogenium, with levels of hybridization for Methanogenium aggregans of $32 \%$ or less with Methanogenium marisnigri $\mathrm{JR}^{\mathrm{T}}$ ( $\mathrm{T}=$ type strain), Methanogenium bourgense MS2 ${ }^{\mathrm{T}}$, Methanogenium olentangyi RC/ER ${ }^{\mathrm{T}}$, Methanogenium thermophilicum UCLA, and Methanogenium tationis DSM $2702^{\mathrm{T}}$. These DNA-DNA hybridization studies also showed that strain $\mathrm{Z}^{\mathrm{T}}$ is closely related to Methanogenium aggregans and Methanocorpusculum parvum, but not so closely as to be placed in the same species. We report here the isolation and characterization of strain $\mathrm{Z}^{\mathrm{T}}$ and propose that it should be named Methanocorpusculum labreanum sp. nov.

(Portions of the results were reported previously [L. Xun, D. R. Boone, and R. A. Mah, Abstr. Am. Soc. Microbiology 1988, I24, p. 185].)

\section{MATERIALS AND METHODS}

Sample collection. The sample was collected from an active, gas-producing area of Tar Pit Lake at the LaBrea Tar Pits in Los Angeles, Calif. A 250-ml polypropylene bottle was half-filled with surface (upper-5-cm) sediment, then filled to the top with water from the lake, and transported to our laboratory. The bottle was placed inside an anaerobic chamber and mixed to suspend the sediment, and $0.5 \mathrm{ml}$ of the resulting slurry was inoculated into $5 \mathrm{ml}$ of enrichment medium in a serum tube. This culture was removed from the chamber, and the gas phase was exchanged with $\mathrm{H}_{2}-\mathrm{CO}_{2}$.

\footnotetext{
* Corresponding author.

† Present address: Chengdu Biogas Scientific Institute, Chengdu, People's Republic of China.
}

Culture media. Enrichment medium contained (per liter of deionized water) $50 \mathrm{mM}$ sodium formate, $2 \mathrm{~g}$ of Trypticase peptone (BBL Microbiology Systems, Cockeysville, Md.), 2 $\mathrm{g}$ of yeast extract, $5 \mathrm{~g}$ of $\mathrm{NaHCO}_{3}, 1 \mathrm{~g}$ of $\mathrm{NH}_{4} \mathrm{Cl}, 0.4 \mathrm{~g}$ of $\mathrm{K}_{2} \mathrm{HPO}_{4}, 0.2 \mathrm{~g}$ of $\mathrm{KH}_{2} \mathrm{PO}_{4}, 0.1 \mathrm{~g}$ of $\mathrm{MgCl}_{2} \cdot 6 \mathrm{H}_{2} \mathrm{O}, 0.5 \mathrm{~g}$ of $\mathrm{L}$-cysteine hydrochloride, and $0.2 \mathrm{~g}$ of $\mathrm{Na}_{2} \mathrm{~S} \cdot 9 \mathrm{H}_{2} \mathrm{O}$. The gas phase was $\mathrm{H}_{2}-\mathrm{CO}_{2}(4: 1)$ pressurized to $152 \mathrm{kPa}$; the final $\mathrm{pH}$ of the medium was 7.0.

Agar medium for roll tubes contained (per liter of deionized water) $15 \mathrm{~g}$ of sodium formate, $1.5 \mathrm{~g}$ of sodium acetate, $2 \mathrm{~g}$ of Trypticase peptone, $2 \mathrm{~g}$ of yeast extract, $1 \mathrm{~g}$ of $\mathrm{NaHCO}_{3}, 1 \mathrm{~g}$ of $\mathrm{NH}_{4} \mathrm{Cl}, 0.4 \mathrm{~g}$ of $\mathrm{K}_{2} \mathrm{HPO}_{4}, 0.2 \mathrm{~g}$ of $\mathrm{KH}_{2} \mathrm{PO}_{4}$, $0.1 \mathrm{~g}$ of $\mathrm{MgCl}_{2} \cdot 6 \mathrm{H}_{2} \mathrm{O}, 0.8 \mathrm{~g}$ of $\mathrm{NaCl}, 0.5 \mathrm{~g}$ of L-cysteine hydrochloride, $0.2 \mathrm{~g}$ of $\mathrm{Na}_{2} \mathrm{~S} \cdot 9 \mathrm{H}_{2} \mathrm{O}$, and $150 \mathrm{~g}$ of purified agar. The gas phase was $\mathrm{N}_{2}$, and the $\mathrm{pH}$ was 6.8 .

The liquid medium used for characterization of the isolate contained (per liter of deionized water) $2 \mathrm{~g}$ of Trypticase peptone, $2 \mathrm{~g}$ of yeast extract, $0.34 \mathrm{~g}$ of sodium acetate, $3.8 \mathrm{~g}$ of $\mathrm{NaHCO}_{3}, 2.5 \mathrm{~g}$ of $\mathrm{NaCl}, 1 \mathrm{~g}$ of $\mathrm{NH}_{4} \mathrm{Cl}, 0.1 \mathrm{~g}$ of $\mathrm{MgCl}_{2} \cdot 6 \mathrm{H}_{2} \mathrm{O}, 0.1 \mathrm{~g}$ of $\mathrm{CaCl}_{2} \cdot 2 \mathrm{H}_{2} \mathrm{O}, 0.4 \mathrm{~g}$ of $\mathrm{K}_{2} \mathrm{HPO}_{4}, 0.5$ $\mathrm{g}$ of $\mathrm{L}$-cysteine hydrochloride, $0.25 \mathrm{~g}$ of $\mathrm{Na}_{2} \mathrm{~S} \cdot 9 \mathrm{H}_{2} \mathrm{O}, 10 \mathrm{ml}$ of a trace mineral solution (3), and $1 \mathrm{mg}$ of resazurin. The medium was prepared with a gas phase of $\mathrm{N}_{2}-\mathrm{CO}_{2}(7: 3)$, and the final $\mathrm{pH}$ was 7.2. After inoculation, pure $\mathrm{H}_{2}(69 \mathrm{kPa}$ of overpressure) was added.

Additions to the media were made from sterile, $\mathrm{O}_{2}$-free stock solutions. These were normally sterilized by autoclaving, but antibiotic solutions were prepared fresh in $\mathrm{O}_{2}$-free water and sterilized by filtration.

Culture methods. The modified (1) culture techniques of Hungate (4) were used throughout these studies. During growth on $\mathrm{H}_{2}-\mathrm{CO}_{2}$, gas was frequently replenished by adding $\mathrm{H}_{2}-\mathrm{CO}_{2}(3: 1)$ to a total pressure of $151 \mathrm{kPa}$. Growth rates were determined from methane production, and the methane produced during growth of the inoculum was included when growth rates were calculated (11). During investigation of optimal $\mathrm{pH}$, temperature, and salt concentration, methane production was not uncoupled from growth. This was established by noting an exponential increase in methanogenesis during growth and by transferring the late-exponential-phase cultures to fresh medium and observing the expected rates of methanogenesis. Experiments to determine optimal growth conditions were also performed with formate as the sub- 
strate in roll tube medium without agar; the growth responses to environmental conditions were similar although the absolute growth rates were slightly less.

Analytical methods. Methane was quantified by gas chromatography with thermal conductivity detection. DNA was obtained after lysing cells by adding $0.2 \mathrm{~g}$ of sodium dodecyl sulfate per liter; DNA was extracted by the method of Marmur (7), and its density was determined by centrifugation in $\mathrm{CsCl}$ gradients immobilized after centrifugation by polymerization of acrylamide (12). Clostridium perfringens ( $\rho$ was assumed to be $1.691 \mathrm{~g} / \mathrm{cm}^{3}$ [14]; Sigma Chemical Co., St. Louis, Mo.) and Micrococcus lysodeikticus ( $\rho$ was assumed to be $1.731 \mathrm{~g} / \mathrm{cm}^{3}$ [14]; Sigma) were used as internal standards for determining buoyant density. The $\mathrm{G}+\mathrm{C}$ content was calculated from the density by using the formula of Schildkraut et al. (14). Epifluorescence was determined microscopically by using a type $\mathrm{O} 2$ filter set (Carl Zeiss, Inc., Thornwood, N.Y.); this provided an excitation spectrum with a peak at $365 \mathrm{~nm}$ and a cutoff at $395 \mathrm{~nm}$ and a 420-nm long-pass barrier filter.

\section{RESULTS AND DISCUSSION}

Isolation of strain $\mathbf{Z}^{\mathbf{T}}$. Enrichment medium with $\mathrm{H}_{2}-\mathrm{CO}_{2}$ as the substrate was inoculated with a sediment slurry from Tar Pit Lake. This enrichment culture was incubated at $37^{\circ} \mathrm{C}$ until methanogenesis was complete. The culture was serially diluted, and dilutions were inoculated into roll tube medium containing formate as the substrate. After the roll tube cultures were incubated for 1 week at $37^{\circ} \mathrm{C}$, pinpoint colonies with epifluorescence characteristic of methanogens were observed. These colonies grew to a maximum diameter of $0.5 \mathrm{~mm}$ within 15 days after inoculation. An epifluorescent colony was picked, inoculated into liquid medium, and incubated until methanogenesis was complete. Microscopic examination revealed that the culture was not axenic, although it probably contained a single strain of methanogen. We maintained this mixed culture by periodic transfer into fresh medium. After several unsuccessful isolation attempts in which we diluted the culture and inoculated roll tube media, we grew the mixed culture in enrichment medium supplemented with (per liter of liquid culture medium) $0.1 \mathrm{~g}$ of D-cycloserine and $2 \mathrm{~g}$ of penicillin $\mathrm{G}$, which eliminated most of the contaminating heterotrophs. We also included these antibiotics at the same concentrations in roll tube media which were inoculated with dilutions of this liquid culture. When these roll tube cultures were incubated, only pinpoint, epifluorescent colonies were observed; all surface colonies had a similar appearance, as did the subsurface colonies. A colony was picked, diluted in liquid medium without antibiotics, and inoculated into fresh roll tube medium without antibiotics. After incubation, the colonies which appeared were all epifluorescent. The surface colonies were tan, circular, clear, and convex with entire edges. A colony was picked and inoculated into liquid medium. This culture, strain $Z^{\mathrm{T}}$, was axenic as indicated by microscopic examination and by its formation of a single colony type when it was inoculated into roll tube medium. It was subsequently deposited in the Oregon Graduate Center Collection of Methanogenic Archaeobacteria (Oregon Graduate Center, Beaverton) as strain OGC $1^{\mathrm{T}}$.

Morphology. The cells were coccoid and 0.4 to $2.0 \mu \mathrm{m}$ in diameter. The degree of irregularity was dependent on the physiological state of the cells and on the ionic strength of the medium; the cells were less irregular in liquid medium containing $5 \mathrm{~g}$ of $\mathrm{NaCl}$ per liter than in medium containing 20

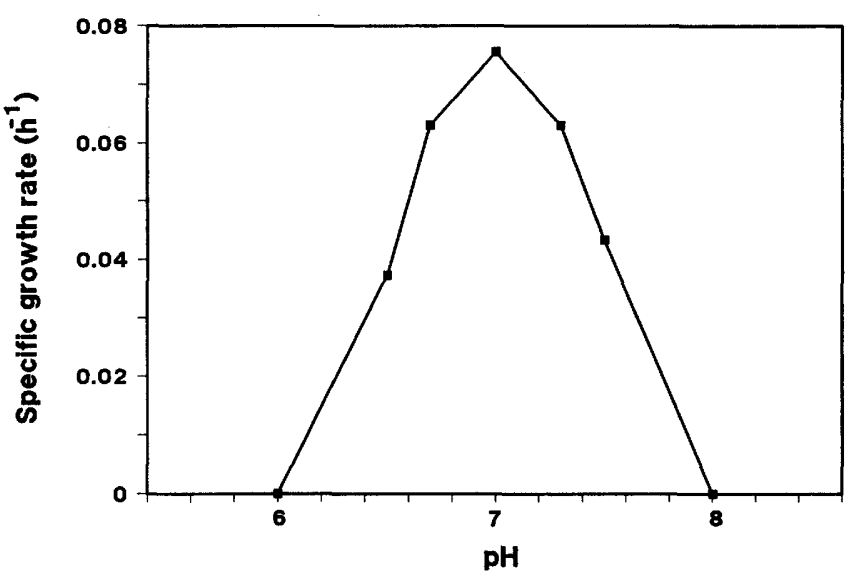

FIG. 1. Effect of $\mathrm{pH}$ on the specific growth rate of strain $\mathrm{Z}^{\mathrm{T}}$.

or $25 \mathrm{~g}$ of $\mathrm{NaCl}$ per liter. In medium without added acetate growth was slower, and the cells were also more regular. Examination of cells in hanging-drop slides prepared in the absence of $\mathrm{O}_{2}$ revealed no motility, and no flagella were observed in negatively stained electron micrographs. Thin sections were prepared by standard fixation techniques with glutaraldehyde and osmium and embedded in Spurr plastic. Transmission electron micrographs of these sections revealed a surface protein (diameter, about $25 \mathrm{~nm}$ ) which was hexagonally closely packed.

Substrates. The ability of strain $\mathrm{Z}^{\mathrm{T}}$ to grow on substrates other than $\mathrm{H}_{2}-\mathrm{CO}_{2}$ was tested by replacing $\mathrm{H}_{2}$ with the following substrates (at concentrations of $20 \mathrm{mM}$ ): sodium formate, sodium acetate, sodium propionate, methanol, trimethylamine, and ethanol. Only sodium formate supported methanogenesis compared with controls without added substrate.

Optimal pH. The optimal pH for growth and methanogenesis was determined by inoculating strain $\mathrm{Z}^{\mathrm{T}}$ into medium previously adjusted to various $\mathrm{pH}$ values by adding $1 \mathrm{M} \mathrm{HCl}$ or $1 \mathrm{M} \mathrm{NaOH}$. Growth occurred over a narrow range of $\mathrm{pH}$ values ( $\mathrm{pH} 6.5$ to 7.5 ), and the optimum $\mathrm{pH}$ for growth was about 7.0 (Fig. 1).

Optimum temperature. Growth rates measured at various temperatures (Fig. 2) indicated an optimum temperature of about $37^{\circ} \mathrm{C}$ for this organism.

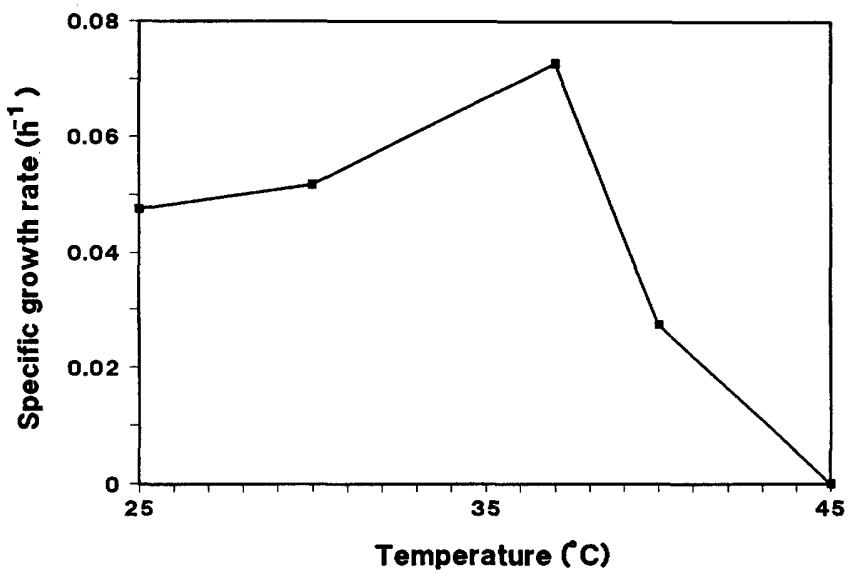
$\mathrm{Z}^{\mathrm{T}}$.
FIG. 2. Effect of temperature on the specific growth rate of strain 


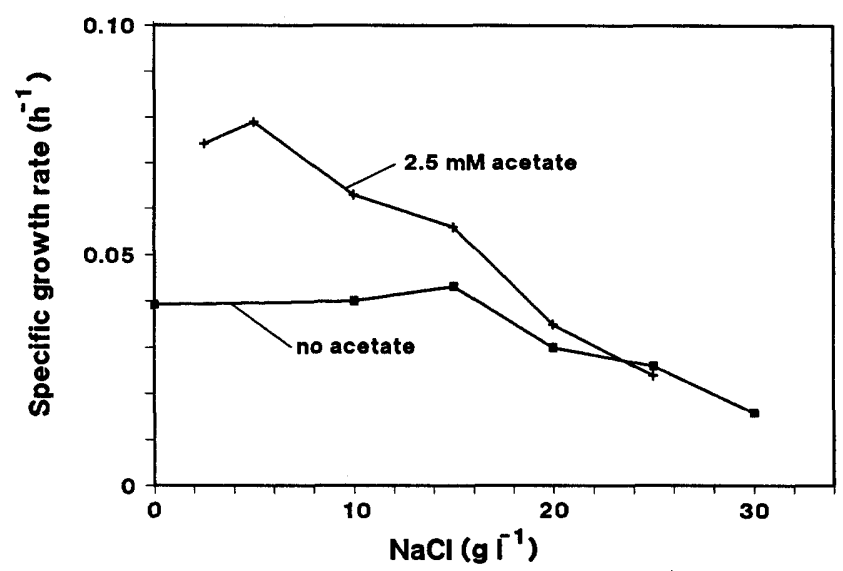

FIG. 3. Effect of $\mathrm{NaCl}$ concentration on the specific growth rate of strain $\mathrm{Z}^{\mathrm{T}}$. The concentrations of $\mathrm{Na}^{+}$from other medium constituents were about $46 \mathrm{mM}$ (equivalent to the $\mathrm{Na}^{+}$contribution of 2.6 $\mathrm{g}$ of $\mathrm{NaCl}$ per liter) for medium without acetate and $48 \mathrm{mM}$ (equivalent to $2.8 \mathrm{~g}$ of $\mathrm{NaCl}$ per liter) for medium with $2.5 \mathrm{mM}$ acetate.

Optimum $\mathrm{NaCl}$ concentration and effect of acetate on growth rate. Figure 3 shows that strain $\mathrm{Z}^{\mathrm{T}}$ grew poorly in the presence of elevated levels of salt, both in the presence and in the absence of sodium acetate. At lower salt levels (less than $15 \mathrm{~g}$ of $\mathrm{NaCl}$ per liter), growth was more rapid and was stimulated by sodium acetate. At high salt concentrations acetate did not stimulate faster growth, perhaps because acetate is more stimulatory when conditions otherwise allow rapid growth.

Growth factor requirements. Strain $\mathrm{Z}^{\mathrm{T}}$ required one or more organic compounds contained in Trypticase peptone or yeast extract (or cysteine). The organism was unable to grow when these compounds were omitted from the medium, even if acetate was included. Adding ash from Trypticase peptone and yeast extract did not relieve the requirement for the presence of these nutrients in the medium.

$\mathbf{G}+\mathbf{C}$ content of the DNA. The $\mathrm{G}+\mathrm{C}$ content of the DNA was $50 \mathrm{~mol} \%$.

Taxonomy. Methanogenium, Methanococcus, and Methanocorpusculum are the only genera which contain coccoid methanogens that are able to use $\mathrm{H}_{2}-\mathrm{CO}_{2}$ and formate as substrates. Methanosphaera (8) and some genera of the Methanosarcinaceae (5) contain coccoid members that are able to use $\mathrm{H}_{2}-\mathrm{CO}_{2}$, but members of these genera can also dissimilate methyl compounds, and none can use formate (6). The ability to use methyl compounds is an important taxonomic characteristic of methanogens (6). The DNA of strain $\mathrm{Z}^{\mathrm{T}}$ had a G $+\mathrm{C}$ content of $50 \mathrm{~mol} \%$, indicating that it is not a member of the genus Methanococcus, whose members have a $\mathrm{G}+\mathrm{C}$ content range of 31 to $33 \mathrm{~mol} \%$. Studies of interspecies hybridization of DNA (Xun et al., submitted) indicated that strain $\mathrm{Z}^{\mathrm{T}}$ is more closely related to Methanocorpusculum parvum (31\%) and Methanogenium aggregans (48\%) than to other species of Methanogenium ( -6 to $18 \%$ ). The small coccoid morphology of strain $\mathrm{Z}^{\mathrm{T}}$ is also similar to that of Methanocorpusculum parvum and Methanogenium aggregans. We propose Methanocorpusculum labreanum as a new species of methanogen, with strain $Z$ as the type strain.

Description of Methanocorpusculum labreanum sp. nov. Methanocorpusculum labreanum (la.bre.an'um. N.L. neu. adj. labreanum, of the LaBrea Tar Pits, Los Angeles, Calif.) cells are irregular, nonmotile cocci that are 0.4 to $2.0 \mu \mathrm{m}$ in diameter and exhibit a negative Gram reaction. They have a protein cell wall and are susceptible to lysis by $0.02 \mathrm{~g}$ of sodium dodecyl sulfate per liter. Surface colonies are tan, circular, clear, and convex with entire edges. $\mathrm{H}_{2}-\mathrm{CO}_{2}$ and formate are the only substrates for growth and methanogenesis. Trypticase peptone or yeast extract is required, and acetate may be stimulatory.

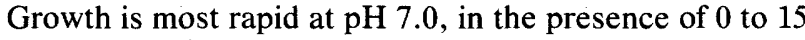
$\mathrm{g}$ of $\mathrm{NaCl}$ per liter, and at $37^{\circ} \mathrm{C}$.

The $\mathrm{G}+\mathrm{C}$ content of the DNA is $50 \mathrm{~mol} \%$, as determined by its density in $\mathrm{CsCl}$ compared with the densities of $C$. perfringens and Micrococcus lysodeikticus.

The type strain is strain Z (= OGC $1=$ DSM 4855), which was isolated from surface sediments of Tar Pit Lake at the La Brea Tar Pits in Los Angeles, Calif.

\section{ACKNOWLEDGMENTS}

We thank Henry Aldrich and Donna S. Williams, University of Florida, Gainesville, for preparing electron micrographs, Indra $\mathrm{M}$. Mathrani for determining the buoyant density of the DNA, Yitai Liu for helpful discussions, and Thomas O. MacAdoo, Virginia Polytechnic Institute and State University, Blacksburg, for help with the orthography of the species epithet.

This work was supported by grants $480-323-4023$ and IFAS-GRIFIA-MCS 2171 from the Gas Research Institute and the Institute of Food and Agricultural Sciences, University of Florida.

\section{LITERATURE CITED}

1. Balch, W. E., and R. S. Wolfe. 1976. New approach to the cultivation of methanogenic bacteria: 2-mercaptoethanesulfonic acid (HS-CoM)-dependent growth of Methanobacterium ruminantium in a pressurized atmosphere. Appl. Environ. Microbiol. 32:781-791.

2. Corder, R. E., L. A. Hook, J. M. Larkin, and J. I. Frea. 1983. Isolation and characterization of two new methane-producing cocci: Methanogenium olentangyi, sp. nov., and Methanococcus deltae, sp. nov. Arch. Microbiol. 134:28-32.

3. Ferguson, T. J., and R. A. Mah. 1983. Isolation and characterization of an $\mathrm{H}_{2}$-oxidizing thermophilic methanogen. Appl. Environ. Microbiol. 45:265-274.

4. Hungate, R. E. 1969. A roll tube method for cultivation of strict anaerobes, p. 117-132. In R. Norris and D. W. Ribbons (ed.), Methods in microbiology, vol. 3B. Academic Press, Inc., New York.

5. Liu, Y., D. R. Boone, R. Sleat, and R. A. Mah. 1985. Methanosarcina mazei $\mathrm{LYC}$, a new methanogenic isolate which produces a disaggregating enzyme. Appl. Environ. Microbiol. 49: 608-613.

6. Mah, R. A., and D. A. Kuhn. 1984. Rejection of the type species Methanosarcina methanica (Approved Lists 1980), conservation of the genus Methanosarcina with Methanosarcina barkeri (Approved Lists 1980) as the type species, and emendation of the genus Methanosarcina. Int. J. Syst. Bacteriol. 34:266-267.

7. Marmur, J. 1961. A procedure for the isolation of deoxyribonucleic acid from micro-organisms. J. Mol. Biol. 3:208-218.

8. Miller, T. L., and M. J. Wolin. 1985. Methanosphaera stadtmaniae gen. nov., sp. nov.: a species that forms methane by reducing methanol with hydrogen. Arch. Microbiol. 141:116122.

9. Ollivier, B. M., R. A. Mah, J. L. Garcia, and D. R. Boone. 1986. Isolation and characterization of Methanogenium bourgense $\mathrm{sp}$ nov. Int. J. Syst. Bacteriol. 36:297-301.

10. Ollivier, B. M., R. A. Mah, J. L. Garcia, and R. Robinson. 1985. Isolation and characterization of Methanogenium aggregans $\mathrm{sp}$ nov. Int. J. Syst. Bacteriol. 35:127-130.

11. Powell, G. E. 1983. Interpreting the gas kinetics of batch cultures. Biotechnol. Lett. 5:437-440.

12. Preston, J. F., and D. R. Boone. 1973. Analytical determination of the buoyant density of DNA in acrylamide gels after prepar- 
ative $\mathrm{CsCl}$ gradient centrifugation. FEBS Lett. 37:321-324.

13. Rivard, C. J., and P. H. Smith. 1982 . Isolation and characterization of a thermophilic marine methanogenic bacterium, Methanogenium thermophilicum sp. nov. Int. J. Syst. Bacteriol. 32: $430-436$.

14. Schildkraut, C. L., J. Marmur, and P. Doty. 1962. Determination of the base composition of deoxyribonucleic acid from its buoyant density in CsCl. J. Mol. Biol. 4:430-443.

15. Zabel, H. P., H. König, and J. Winter. 1984. Isolation and characterization of a new coccoid methanogen, Methanogenium tatii spec. nov. from a solfataric field on Mount Tatio. Arch. Microbiol. 137:308-315.

16. Zabel, H. P., H. König, and J. Winter. 1985. Emended description of Methanogenium thermophilicum, Rivard and Smith, and assignment of new isolates to this species. Syst. Appl. Microbiol. 6:72-78.

17. Zellner, G., C. Alten, E. Stackebrandt, E. Conway de Macario, and J. Winter. 1987. Isolation and characterization of Methanocorpusculum parvum, gen. nov., spec. nov., a new tungsten requiring, coccoid methanogen. Arch. Microbiol. 147:13-20. 